\title{
Cirurgia ortognática de modelos: protocolo para mandíbula
}

\author{
Eduardo Sant'Ana*, Moacyr Tadeu Vicente Rodrigues**, Gabriel Ramalho Ferreira***, \\ Júlio de Araújo Gurgel****
}

\begin{abstract}
Resumo
Introdução: o ensaio em modelos de gesso tem grande importância para o planejamento em cirurgia ortognática. Objetivo: neste artigo, será apresentado, passo-a-passo, uma técnica de cirurgia de modelos iniciando pela mandíbula, destacando aspectos importantes e as vantagens deste procedimento.
\end{abstract}

Palavras-chave: Cirurgia ortognática. Cirurgia de modelos. Planejamento em Cirurgia Ortognática.

\section{INTRODUÇÃO}

Tradicionalmente, nas cirurgias combinadas, a maxila era reposicionada primeiramente. Buckley et al. ${ }^{6}$ foram os primeiros a sugerir e descrever uma seqüência de cirurgia combinada, iniciando pela mandíbula. Estes autores afirmaram que esta técnica prevenia possíveis deslocamentos da maxila reposicionada, quando a cirurgia era iniciada pela mandibula. Isto foi verificado especialmente em cirurgias de grande avanço mandibular, quando a segmentação da maxila era necessária e/ou na presença de maxila com paredes ósseas delgadas, tornando difícil qualquer fixação com miniplacas, além de comprometer a estabilidade ${ }^{7}$.

Algumas desvantagens foram descritas, na época, tais como fixação rígida obrigatória para a mandíbula, além dos riscos potenciais de uma fratura precipitada da osteotomia sagital. Porém, considerando os avanços no campo da cirurgia ortognática (técnicas cirúrgicas, instrumentais, materiais e métodos de fixação), estes fatores não mais contam como desvantagens, desconsiderando-se, é claro, a experiência e habilidade do cirurgião ${ }^{6}$.

A cirurgia dos modelos é uma importante etapa do planejamento, imprescindível para o sucesso das cirurgias ortognáticas combinadas. Eliminar limitações durante as etapas do planejamento (análise facial, traçado predictivo, cirurgia de modelos) é a busca incessante das pesquisas nesta área. A etapa laboratorial de cirurgia nos modelos, principalmente a tradicional conduzida a partir do modelo superior, quando feita diretamente no articulador semi-ajustável, torna-se uma tarefa difícil e, na maioria das vezes, imprecisa ${ }^{8}$. Primeiramente, deve-se considerar a ação da gravidade sobre este modelo em movimentação, estabilizado apenas com cera. Segundo, muitas vezes há maior risco de imprecisão na obtenção das medidas a serem alteradas e na manutenção da estabilidade destas até a confecção do guia cirúrgico (goteira e splint) ${ }^{8}$.

Desde o início das publicações sobre cirurgias combinadas iniciadas pela mandíbula, houve a

* Professor Doutor da Disciplina de Cirurgia da FOB-USP. Membro do Advanced Orthognathic Surgery Foundation

** Aluno de Mestrado em Estomatologia da FOB-USP.

*** Estagiário da Disciplina de Cirurgia da FOB-USP.

**** Professor Doutor da Disciplina de Cirurgia da FOB-USP. 
necessidade de se adaptar vários aspectos no planejamento, entre eles o ensaio cirúrgico em modelos. Neste artigo, portanto, será apresentada, passo-a-passo, a execução da cirurgia de modelos para cirurgia ortognática combinada iniciada pela mandíbula, adaptada a partir da técnica descrita por Ellis III ${ }^{8}$.

\section{CIRURGIA NOS MODELOS INICIANDO PELA MANDÍBULA}

Após a montagem correta dos modelos em relação central em articulador semi-ajustável, alguns parâmetros devem ser conferidos:

- o pino incisal deve tocar a mesa incisal;

- o pino incisal deve estar ajustado ao ponto zero e este ajuste deve ser mantido durante todo o procedimento.

Com estes ajustes concluídos, é importante identificar os lados direito (D) e esquerdo (E).

\section{PROCEDIMENTO PROPRIAMENTE DITO}

O pino incisal deve ser removido para que as linhas médias dentárias da maxila e da mandíbula sejam marcadas a lápis. Com a porção posterior do articulador voltada para o profissional, olhando somente um dos lados por vez, desenha-se uma linha vertical reta, desde o articulador, passando pelo modelo inferior, na região de molares. Quando observada do lado esquerdo, a linha vertical traçada do lado direito parece não estar correta, pois o ângulo de visão será diferente.

A partir desta fase, na qual as linhas de referência foram traçadas, pode-se remover o modelo inferior do articulador e fixá-lo ao bloco metálico referencial pertencente à plataforma de Erickson para cirurgia de modelos Great Lakes DigimaticGLD (Great Lakes Orthodontic Ltd, Tonawanda, $\mathrm{NY}$ ), que é uma mesa equipada com paquímetro digital para aferição das movimentações necessárias (Fig. 1).

Para maior confiabilidade e segurança nas aferições, a borda incisal do incisivo central esquerdo, as cúspides dos caninos e as cúspides mesiovestibulares dos segundos molares devem ser marcadas a lápis, pois serão os pontos de referência para o registro das medidas verticais da mandíbula.

As aferições nesta fase são necessárias para que as medidas verticais, ântero-posterior e transversal sejam tomadas e anotadas em uma ficha, no tópico "modelo inicial", ou seja, medidas do modelo inicial, como preconizado por Arnett et al. ${ }^{2}$ (Fig. 2), com pequenas modificações em relação à técnica de cirurgia de modelos preconizada por Ellis $\mathrm{III}^{8}$, para as medidas verticais (direita e esquerda), horizontal e transversal.

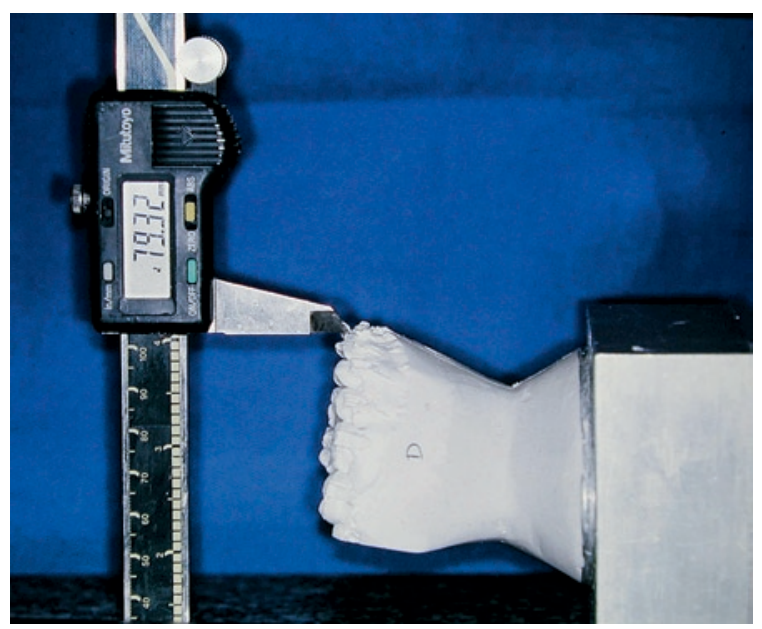

FIGURA 1 - Modelo inferior, acoplado à base metálica de referência, sendo aferido utilizando a GLD.

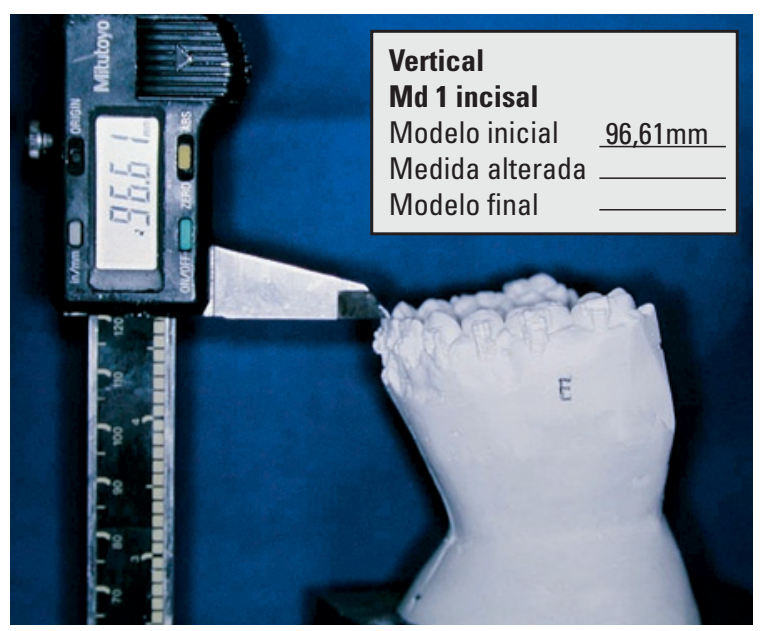

FIGURA 2 - Aferição vertical inicial do modelo inferior, tendo como referência a borda incisal do incisivo central. 0 valor é anotado na ficha, no tópico "modelo inicial" para o incisivo inferior. 
Inicialmente, afere-se a altura vertical do incisivo central esquerdo, colocando-se a ponta do paquímetro gentilmente sobre a borda incisal do dente marcado. No caso usado para ilustração, a medida aferida foi 96,61 (Fig. 2).

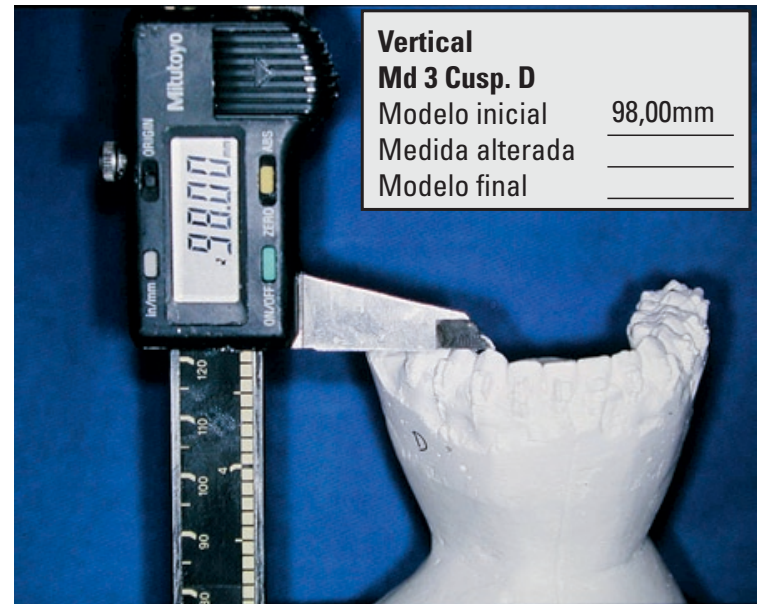

FIGURA 3 - Aferição vertical inicial do modelo inferior, tendo como referência a ponta de cúspide dos dentes 33 e 43 . Os valores são anotados na ficha, no tópico "modelo inicial", para os caninos direito e esquerdo.
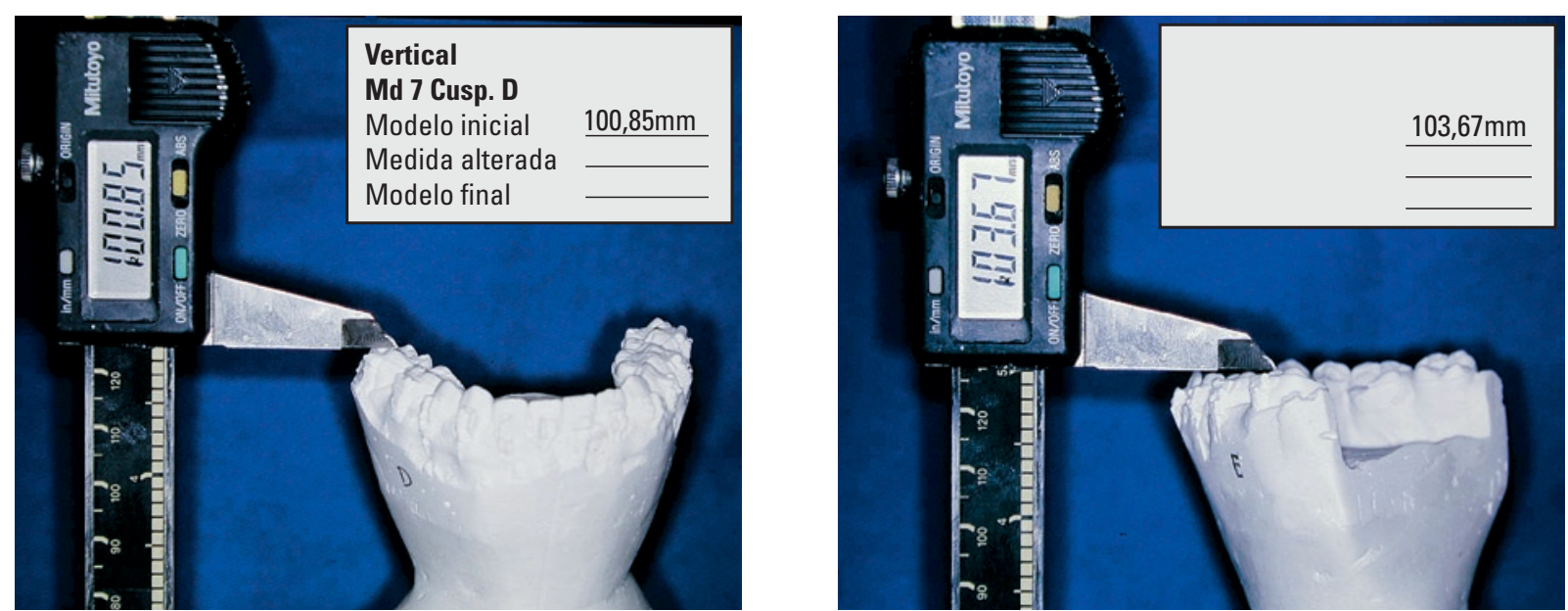

FIGURA 4 - Aferição vertical inicial do modelo inferior, tendo como referência a ponta de cúspide mesiovestibular dos dentes 37 e 47.0 s valores são anotados na ficha, no tópico “modelo inicial”, para os segundos molares direito e esquerdo.

Por fim, tomam-se as medidas verticais dos segundos molares em suas respectivas cúspides mesiovestibulares. Os valores $100,85 \mathrm{~mm}$, para o lado direito, e $103,67 \mathrm{~mm}$, para o lado esquerdo, foram anotados na ficha (Fig. 4).

Para as medidas ântero-posteriores, o bloco
Em seguida, da mesma forma, obtém-se a medida vertical de ambos os caninos nas pontas das cúspides. Foram obtidos os valores de $98,00 \mathrm{~mm}$ e $99,57 \mathrm{~mm}$ para os caninos direito e esquerdo, respectivamente (Fig. 3).

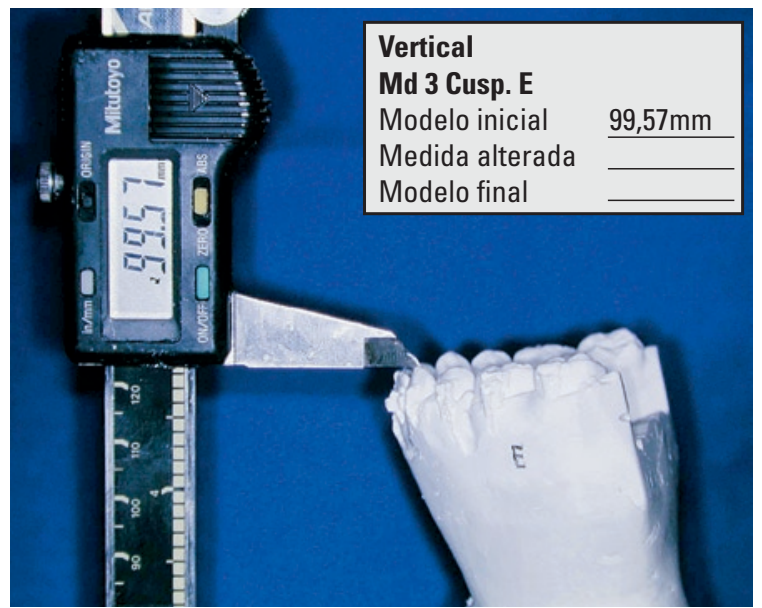

Modelo inicia

Medida alterada

Modelo final

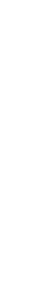




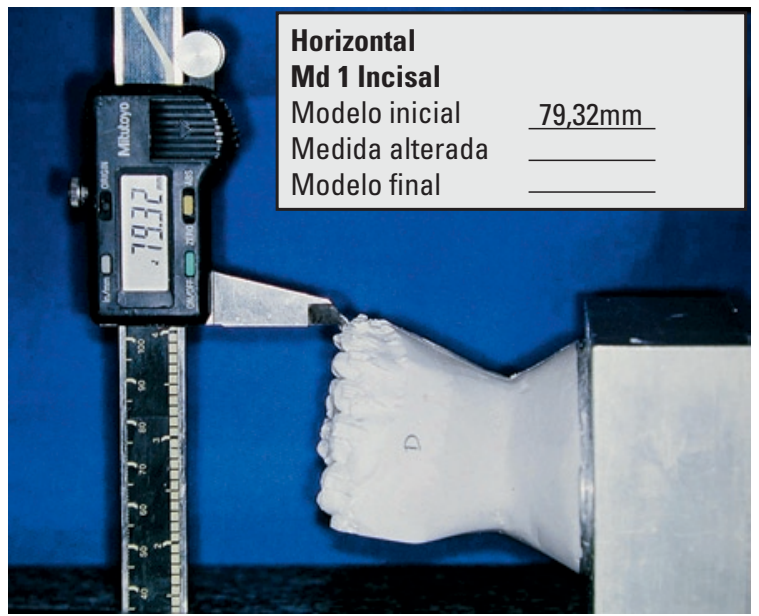

FIGURA 5 - Aferição horizontal inicial (ântero-posterior) do modelo inferior, tendo como referência um ponto demarcado na face vestibular do dente 31. 0 valor é anotado na ficha, no tópico "modelo inicial", para a face vestibular do incisivo central esquerdo.

Neste caso, foi anotado a medida de $79,32 \mathrm{~mm}$ (Fig. 5).

Para a obtenção de uma medida inicial de referência para a linha média, vira-se o bloco com seu lado direito para baixo. Em seguida, posiciona-se a ponta do paquímetro entre os incisivos centrais e toma-se a medida. Para este caso foi obtido o valores de 42,80mm (Fig. 6).

Após a obtenção das medidas do "modelo inicial" e da análise facial, na qual eventualmente são detectadas assimetrias e outros detalhes quanto à dinâmica e o equilíbrio facial, o traçado predictivo digital foi realizado a partir do software Dolphin 9.0 - Imaging \& Management Solutions (Chatsworth, CA). Este programa proporciona ao profissional condições de determinar o planejamento cirúrgico do caso com maior rapidez, comodidade e acurácia, obtendo-se, ao final, uma tabela com as medidas para cada movimentação que o modelo de gesso deverá sofrer, orientando o restabelecimento estético-funcional do paciente ${ }^{9}$.

A partir das medidas do traçado, associadas à análise facial ${ }^{1}$ para cada movimentação ântero-posterior e vertical, obtêm-se os valores a serem alterados, nos três planos do espaço, proporcionando o preenchimento do item "medida alterada" e permitindo o cál-

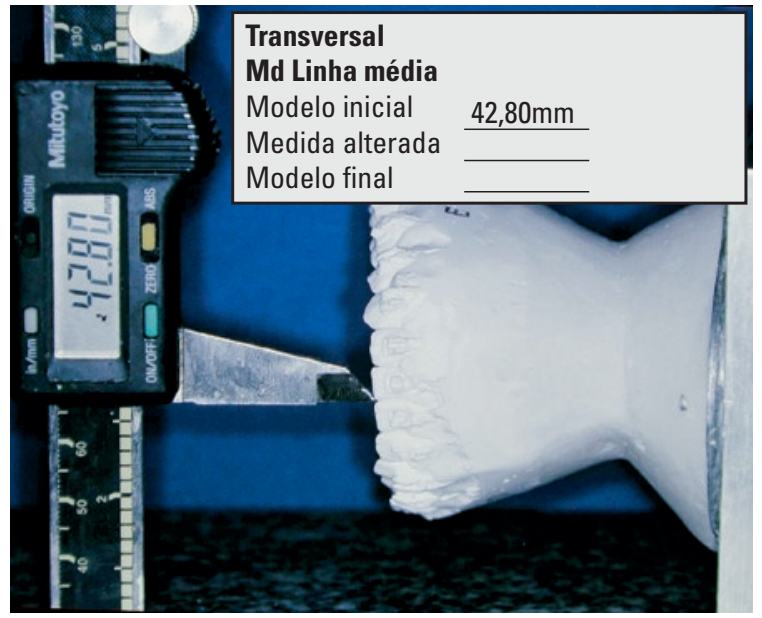

FIGURA 6 - Aferição transversal inicial do modelo inferior, tendo como referência a linha média dentária. 0 valor é anotado na ficha, no tópico “modelo inicial", com o lado direito do modelo para baixo.

culo das medidas finais para o modelo mandibular (Fig. 2-6). Para que esta manobra seja feita de forma precisa, é importante conhecer os três movimentos a serem realizados na cirurgia de modelos:

- movimento horizontal do incisivo central;

- movimento vertical do incisivo central;

- movimento vertical do segundo molar.

Outro aspecto de extrema importância é o significado dos sinais positivo ou negativo para cada movimento específico:

- sinal positivo (+): significa avanço (A-P) ou aumento no sentido vertical;

- sinal negativo (-): significa recuo (A-P) ou diminuição no sentido vertical.

No movimento transversal (lado direito do modelo para baixo):

- sinal positivo $(+)$ : significa rotação para a esquerda (sentido anti-horário);

- sinal negativo (-): significa rotação para a direita (sentido horário).

Já as modificações indicadas para a linha média e para a inclinação dos caninos são determinadas clinicamente e devem ser compensadas avaliandose adequadamente o segmento envolvido (maxila, mandíbula, ou ambos). Para tanto, deve-se aumentar ou diminuir verticalmente o modelo do lado 
envolvido, ou desviar para esquerda ou direita, de acordo com as medidas obtidas clinicamente durante a análise facial.

Em seguida, são feitos os cálculos e obtêm-se os valores desejados para a futura posição do modelo da mandíbula nos sentidos ântero-posterior, vertical e transversal. Após a checagem das medidas, o modelo inferior é separado da base com uma serra fina e afiada (Fig. 7).

Após o corte, realiza-se um desgaste da porção mais inferior (área onde encontra-se a bolacha metálica), principalmente nos casos onde a mandíbula sofrerá rotação horária. Geralmente, um desgaste de $5 \mathrm{~mm}$ a mais do que o indicado

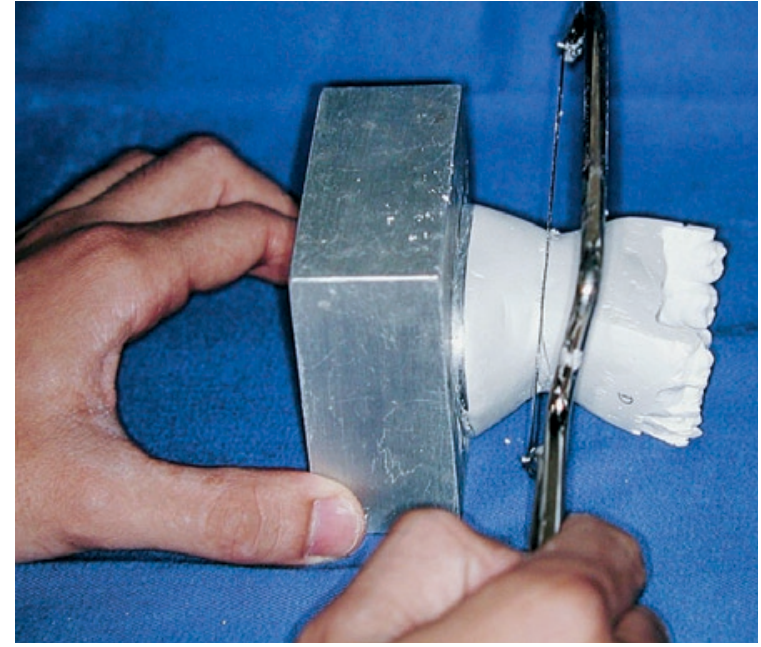

FIGURA 7 - Separação do modelo inferior de sua base.
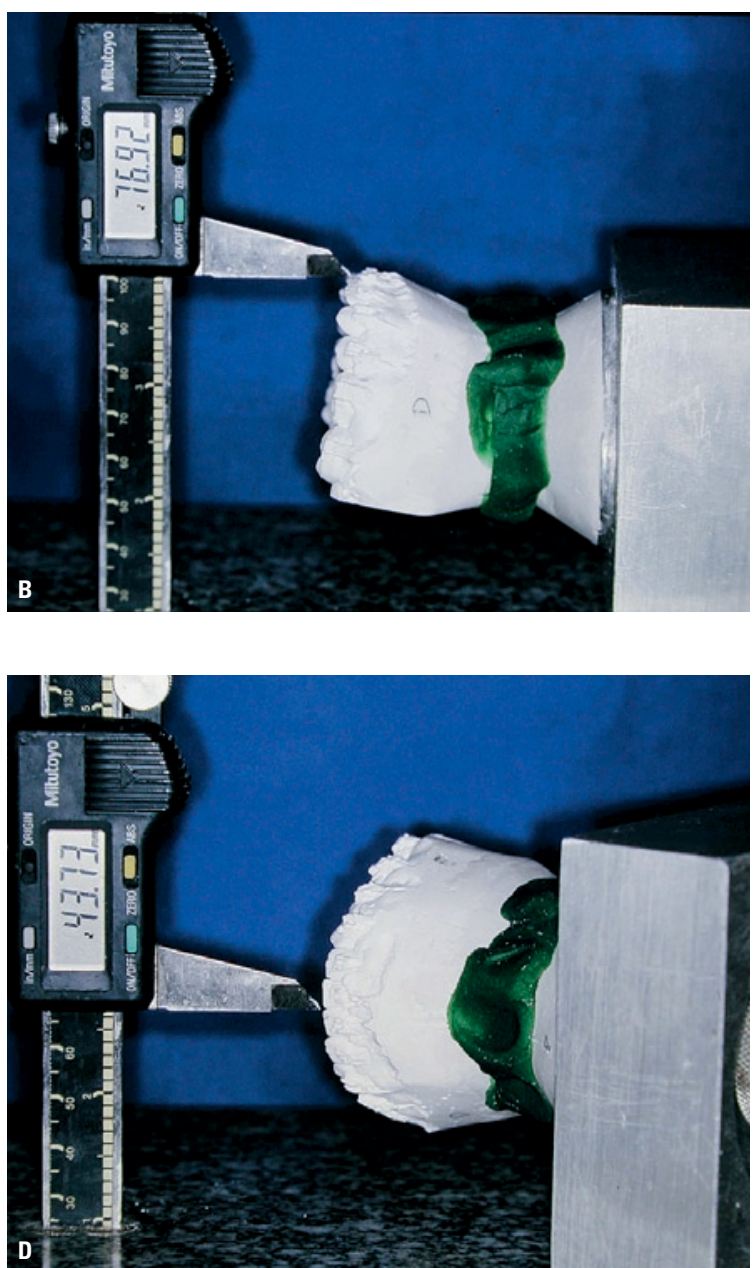

FIGURA 8 - Aferições finais do modelo inferior: A, C) verticais; B) horizontal ou ântero-posterior e D) tranversal, a partir das medidas estabelecidas no planejamento. 
no traçado predictivo é o suficiente para evitar interferências durante o reposicionamento. Coloca-se o segmento mandibular conforme o planejamento, interpondo-se cera branca (mais maleável) entre a base e o modelo. As medidas finais, para cada modificação desejada, devem ser rigorosamente conferidas com a GLD (Fig. 8).

Pode ser necessário adicionar ou remover quantidades variáveis de cera branca ou realizar desgastes no gesso dos segmentos maxilares, para permitir o correto posicionamento do modelo. Terminado o posicionamento, o modelo deve ser novamente acoplado ao articulador, checando-se a linha média e as linhas de referência posteriores da mandíbula, que devem estar alinhadas. Caso estas referências estejam incorretas, deve-se remover o modelo do articulador e adaptar o mesmo à base metálica da GLD. Após a correção, todas as modificações devem ser conferidas novamente. Com estes detalhes checados, uma camada de cera pegajosa deve ser dispensada ao redor da interface gerada pelo corte, para evitar o deslocamento do modelo. A tabela 1 revela as alterações planejadas (medida alterada) e as medidas finais (modelo final), para o caso ilustrado.

\section{CONFECÇÃO DO SPLINT OU GUIA CIRÚRGICO INTERMEDIÁRIO}

Para dar início à confecção deste dispositivo, deve-se limpar toda a superfície oclusal dos dentes de ambos os modelos, para remoção de eventuais resquícios de cera ou gesso, que possam causar interferências. Para se evitar excessos e possível retenção do splint nos braquetes, é interessante o emprego de cera periférica sobre os acessórios do aparelho fixo, nos dois arcos. Os modelos devem ser isolados com vaselina líquida ou isolante para gesso. Para a confecção do splint, utiliza-se a resina acrílica quimicamente ativada. Após sua adequada manipulação - na quantidade correta, em pote de vidro com tampa - aguarda-se a fase plástica ou de trabalho da resina, remove-se do pote e manipula-se a mesma, em formato de
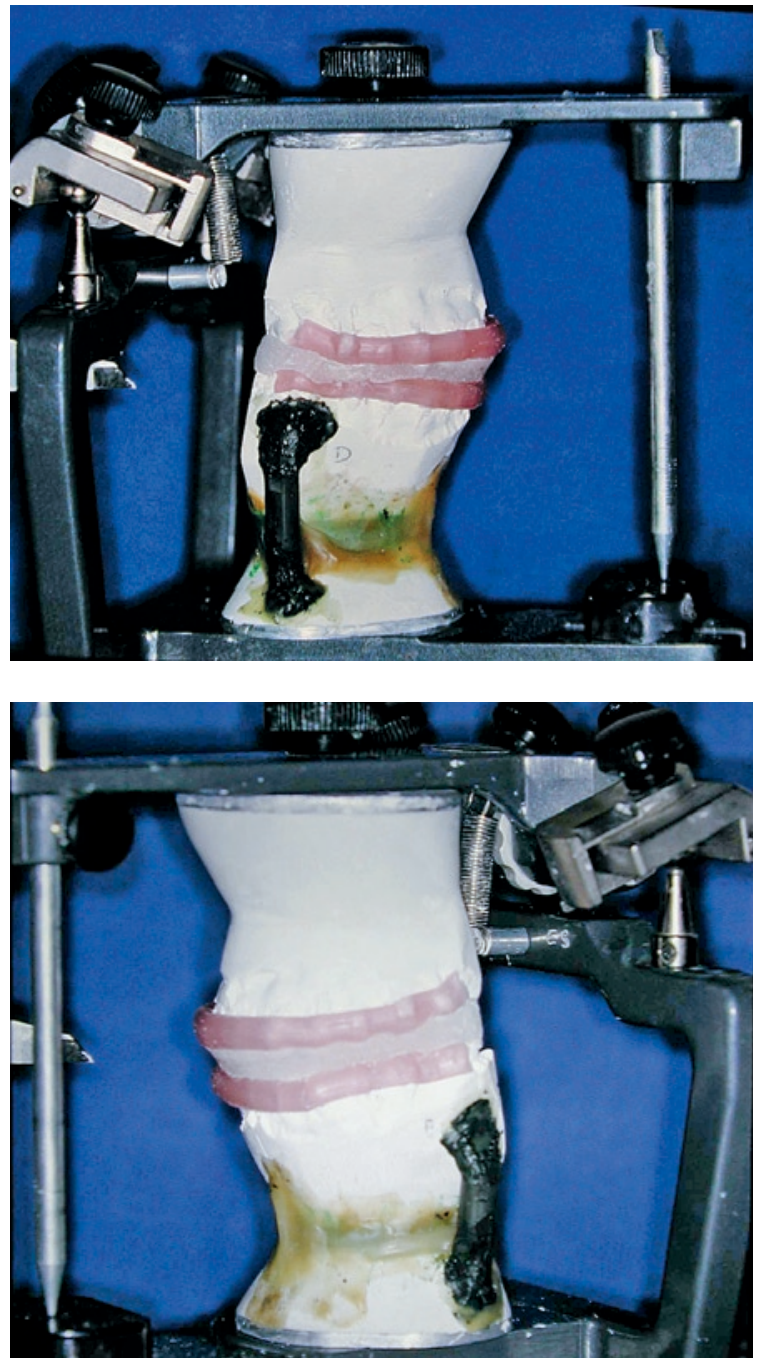

FIGURA 9 - Vistas direita e esquerda do splint intermediário pronto, em posição entre os arcos.

Tabela 1 - Medidas do modelo inicial, medidas alteradas (considerando os sinais, positivo ou negativo), a partir do planejamento, e medidas do modelo final utilizado para ilustração.

\begin{tabular}{cccc}
\hline medidas & $\begin{array}{c}\text { modelo } \\
\text { inicial }\end{array}$ & $\begin{array}{c}\text { medida } \\
\text { alterada }\end{array}$ & $\begin{array}{c}\text { modelo } \\
\text { final }\end{array}$ \\
\hline Md 1 vertical & 96,61 & $-2,20$ & 94,41 \\
Md 3 vertical-D & 98,00 & $+3,30$ & 101,30 \\
Md 3 vertical-E & 99,57 & $+3,10$ & 102,67 \\
Md 7 vertical-D & 103,67 & $+1,33$ & 105,00 \\
Md 7 vertical-E & 100,85 & $+4,01$ & 104,86 \\
Md 1 horizontal & 79,32 & $-2,40$ & 76,92 \\
Md LM transversal & 42,80 & $+0,93$ & 43,73 \\
\hline
\end{tabular}


um arco, colocando-a sobre a superfície oclusal do arco inferior. Fecha-se o articulador, sendo que o pino incisal deve tocar a mesa incisal. Os excessos são removidos com o auxílio de uma espátula ou com uma tesoura, tomando-se o cuidado para não deformar ou não remover quantidades exageradas de resina. Quando a polimerização iniciar, pode-se abrir cuidadosamente o articulador e remover excessos mais grosseiros. Em seguida, deve-se fechar o articulador e aguardar a polimerização total. Para diminuir a ocorrência de distorções da resina, está indicado o emprego de elásticos potentes fechando o articulador, principalmente quando o guia fica espesso em alguns pontos.

Após a completa polimerização da resina, a remoção dos excessos e o acabamento final são realizados com peça de mão e brocas para resina. A cirurgia de modelos deve ser realizada no dia anterior à cirurgia, utilizando-se modelos recentes, idealmente tomados três dias antes da cirurgia. Outros materiais e instrumentos que não foram citados podem, ocasionalmente, ser utilizados em substituição aos que foram ilustrados, desde que não haja comprometimento da técnica e que se obtenham resultados idênticos. Este é um procedimento que exige muito critério e atenção aos detalhes, pois é ele que irá guiar o novo posicionamento da mandíbula em relação à maxila, o que mostra o grau de importância desta fase do planejamento².

\section{DISCUSSÃO}

As cirurgias ortognáticas iniciadas pela mandíbula representam uma opção interessante para o posicionamento da maxila. A maxila, por apresentar pequena espessura em suas paredes ósseas, muitas vezes não oferece uma estabilidade confiável para bloqueio intermaxilar, especialmente em casos de grandes avanços e em cirurgias em que a maxila é segmentada. Considerando os riscos inerentes à cirurgia da mandíbula, fatores anteriormente tidos como limitantes, hoje não são considerados mais como desvantagens desta técnica, tais como a fixação rígida obrigatória e até mesmo o posicionamento condilar ${ }^{6,7}$.

Além disso, os estudos sobre a reabsorção condilar idiopática após a cirurgia ortognática também mostram que a fixação passiva dos cotos ósseos diminui significativamente as chances de problemas articulares pós-operatórios. A fixação da mandíbula utilizando miniplacas e parafusos monocorticais tem se mostrado de grande colaboração para tal passividade na fixação mandibular. Soma-se a esta outras vantagens: não necessitar de incisões extrabucais para realizar a fixação; menor risco de lesão ao feixe vásculo-nervoso alveolar inferior; não comprometer a fixação quando de fraturas indesejadas na lingual do coto distal; e maior grau de satisfação, quanto ao resultado, dos pacientes que recebem este tipo de fixação $0^{3,4,5}$.

\section{CONSIDERAÇÕES FINAIS}

A cirurgia de modelos para a mandíbula é tecnicamente tão simples quanto para a maxila, porém alguns detalhes devem ser considerados, para que não haja equívocos no momento de se calcular as medidas a serem alteradas. A cirurgia ortognática combinada iniciada pela mandíbula mostra-se como opção interessante para o reposicionamento da maxila, desde que aspectos limitantes, como posicionamento condilar e fixação passiva, sejam bem conduzidos e controlados pelo cirurgião. Desta forma, esta técnica, apesar de já ter sido descrita em 1987, em associação com os demais avanços na área da cirurgia ortognática, torna-se cada vez mais bem indicada e com menores limitações, contribuindo para que os resultados clínicos sejam cada vez melhores. 


\title{
Orthognathic model surgery: mandibular protocol
}

\author{
Abstract \\ Introduction: The cast surgery has great importance in orthognatic surgery treatment planning. Aim: In this ar- \\ ticle, a step by step lower model surgery will be presented, emphasizing important details and advantages of this
} procedure.

Key words: Orthognathic surgery. Model block surgery. Orthognathic surgery. Treatment planning.

\section{REFERÊNCIAS}

1. ARNETT, G. W. et al. Soft tissue cephalometric analysis: diagnosis and treatment planning of dentofacial deformity. Am. J. Orthod. Dentofacial Orthop., St. Louis, v. 116, no. 3, p. 239-253, Sept. 1999.

2. ARNETT, G. W.; KIM, J.; SANT'ANA, E.; GIGLIO, F. P. M. Cirurgia ortognática de modelo realizada passo a passo. R. Dental Press Ortodon. Ortop. Facial, Maringá, v. 7, n. 1, p. 93-105, jan./fev. 2002.

3. BORSTLAP, W. A.; STOELINGA, P. J. W.; HOPPENREIJS, T. J. M.; VAN'THOF, M. A. Stabilization of sagittal split advancement osteotomies with miniplates: a prospective, multicentre study with two-year follow-up. Part I- Clinical Parameters. Int. J. Ora Maxillofac. Surg., Copenhagen, v. 33, no. 5, p. 433-441, July 2004.

4. BORSTLAP, W. A.; STOELINGA, P. J. W.; HOPPENREIJS, T. J. M.; VAN'THOF, M. A. Stabilization of sagittal split advancement osteotomies with miniplates: a prospective, multicentre study with two-year follow-up. Part II- Radiographic parameters. Int. J. Oral Maxillofac. Surg., Copenhagen, v. 33, no. 6 , p. 535-542, Sept. 2004.
5. BORSTLAP, W. A.; STOELINGA, P. J. W.; HOPPENREIJS, T. J. M.; VAN'THOF, M. A. Stabilization of sagittal split advancement osteotomies with miniplates: a prospective, multicentre study with two-year follow-up. Part III- Condylar remodeling and resorption. Int. J. Oral Maxillofac. Surg., Copenhagen, v. 33, no. 7, p. 649-655, Oct. 2004

6. BUCKLEY, M. J.; TUCKER, M. R.; FREDETTE, S. A. An alternative approach for staging simultaneous maxillary and mandibular osteotomies. Int. J. Adult Orthod. Orthognath. Surg. Lombard, v. 2, no. 2, p. 75-78, 1987.

7. COTTRELL, D. A.; WOLFORD, L. M. Altered orthognathic surgical sequencing and a modified approach to model surgery. J. Oral Maxillofac. Surg., Philadelphia, v. 52, no. 10, p. 10101020, Oct. 1994

8. ELLIS III, E. Accuracy of model surgery: evaluation of an old technique and introduction of a new one. J. Oral Maxillofac. Surg., Philadelphia, v. 48, no. 11, p. 1161-1167, Nov. 1990.

9. SMITH, J. D.; THOMAS, P. M.; PROFFIT, W. R. A comparison of current prediction imaging programs. Am. J. Orthod. Dentofacial Orthop., St. Louis, v. 125, no. 5, p. 527-536, May 2004.

\author{
Endereço para correspondência \\ Eduardo Santana \\ Alameda Dr. Octavio Pinheiro Brisola, 9-75 \\ Faculdade de Odontologia de Bauru \\ CEP: 17.012-901 - Bauru/SP \\ Email: esantana@usp.br
}

